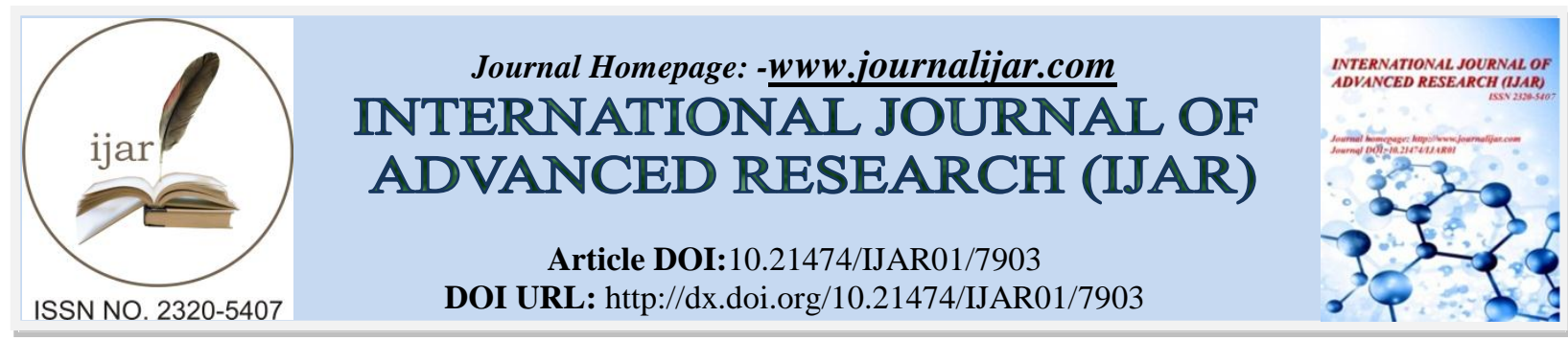

RESEARCH ARTICLE

\title{
RISK FACTORS AND TYPE OF CERVICOVAGINITIS MORE FREQUENTLY IN WOMEN FROM 15 TO 50 YEARS.
}

\section{Betty Sarabia Alcocer ${ }^{1}$, Luis Alberto Núñez Oreza ${ }^{2}$, Betty Mónica Velázquez Sarabia ${ }^{2}$, Priscilla Karmina Velázquez Sarabia ${ }^{1}$, Paulino Tamay Segovia ${ }^{3}$, Selene Blum Domínguez ${ }^{3}$, Patricia Margarita Garma Quen ${ }^{4}$, Rafael Manuel de Jesús Mex Álvarez ${ }^{5}$, and Ángel Arturo Ake Ordoñez ${ }^{6}$.}

1. Faculty of Medicine of the Autonomous University of Campeche.

2. Center for Biomedical Research. Autonomous University of Campeche.

3. Doctor Surgeon graduated from the Faculty of Medicine of the U.A.C.

4. Law graduate and researcher.

5. Faculty of Biological Chemistry.

6. Student of the Licentiate Medical Surgeon.

\section{Manuscript Info}

Manuscript History

Received: 12 August 2018

Final Accepted: 14 September 2018

Published: October 2018

\section{Abstract}

Objective: To determine the type of cervicovaginitis most frequent in women from 15 to 50 years old in San Francisco de Campeche. Material and methods: Observational, cross-sectional, and retrospective study, reviewing a total of 466 patients who attended the Papanicolaou, looking for the age of presentation, their marital status, the level of schooling, their beginning of sexual life, number of sexual partners, the use of contraceptive methods, their socioeconomic level and the type in which the pathology predominates.

Results: Of a total of 460 women who attended the pap smear, 39 presented data of CIN II -NIC III, 80 gave results of cervicovaginitis which was the most frequent candida $(41.25 \%)$.

Conclusions: The social group that experiences the highest risk of suffering from sexually transmitted diseases are adolescent women.

Copy Right, IJAR, 2018,. All rights reserved.

\section{Introduction:-}

Cervico-vaginitis "we describe it as the different degrees of inflammation of the vulva, the vagina and the ectopic endocervical tissue, which can be accompanied by leucorrhoea, pruritus and itching, dysuria and dyspareunia. Approximately $25 \%$ of women who attend the outpatient clinic are diagnosed with a gynecological problem, more than half of the cases are of infectious origin in which sexual transmission plays an important role.

The rest are due to other processes, such as allergic reactions, traumatic, hormonal problems ... etc. Sometimes these causes are overlapped, the diagnosis is more difficult and the process can become chronic. ${ }^{(1)}$

Within its generalities are characterized by the presence of inflammation, drainage and gynecological complications, which do not necessarily have etiology by germs. It is considered that it is one in which the secretion or change of vaginal flora is increased, which in itself can occur in physiological form or changes due to moments of the ovarian cycle, use of oral contraceptives and use of intrauterine device. (2) 
Although modern medical practice has frequently relegated vaginal symptoms to the field of gynecology specialists, the range of clinical pictures and diagnoses included in this category with the concomitant issues of risk prevention and control is ideally suited for physician care. of family. Excellence in the diagnosis and treatment of these diseases should be the standard of care. And they can be achieved with little investment of equipment and time. On the part of the doctor and minimum cost for the patient ${ }^{(3)}$.

The case of cervicovaginitis has been found in 15 years $19 \%$ of outpatients, 10 to $30 \%$ of pregnant women and up to $40 \%$ of those women who attend clinics that deal with sexually transmitted diseases. ${ }^{(4)}$

Regarding its pathophysiology, the female genital tract is one of the regions of the organism normally colonized by germs. The different population and cultural characteristics; the lack of standardization in the taking of vaginal samples; the different laboratory methodologies, make it difficult to reach the conclusion about what is the "normal vaginal flora", preferring the name of "endogenous flora", "indigenous flora" or "usual flora", thus including any microorganism present in the TG and that does not produce pathology, except under certain circumstances or certain associations with infectious processes. ${ }^{(5)}$

The recurrence of vaginitis by Candida is a behavior suggestive of deficient cellular immunity, especially related to diabetes mellitus. When it comes to Trichomonas, the possibility of concurrent venereal infection must be taken into account $^{(2)}$

Among the clinical manifestations of candida albicans we find that there is perivaginal pruritus, whitish secretion, thick and adherent with clots, dysuria, the labia majora are pale or erythematous, in trichomonal vaginitis among its clinical features we find malodorous vaginal discharge, pruritic irritant either yellow or green, foamy, in addition there is dyspareunia, dysuria and abdominal discomfort, vulvar erythema, inflammation of the vaginal wall, strawberry cervix, bacterial vaginitis due to gardnerella, is characterized by bad vaginal odor (fish smell), leucorrhea levo or moderate, homogeneous, viscous, uniformly covers the entire vaginal mucosa, is white ${ }^{(6)}$

It is well known that there are many factors that influence cerviciovaginitis in addition to the presence of menstruation, the use of antibiotics, intrauterine devices, history of surgeries and deliveries, an important factor is the socio-economic level, according to the 1st Consensus Meeting Academic in Family Medicine of Organisms and Educational Institutions and Health, carried out from June 15 to 17, 2005 (3,4) in Mexico City, the economic level was defined with the following classification:

Family poverty level 1, family poverty level 2 and family poverty level 3

The scale establishes that level 3 of poverty is the most serious of all and level 1 is the least serious. Families that can cover the items mentioned in the three levels are not considered poor.

The world health organization considers the cervicovagintis is also conditioning and of greater affectation in the young population and in the sexually active age groups that goes from 18 to 35 years, being in this lapse of life in which greater is the rate of cases of cervicovaginitis, regardless of the germ that originates it. (7)

The reproductive health division of WHO, dedicated to the development of programs aimed at the production of solutions and preventive measures for STDs and childhood and juvenile pathology related to the sexual activity of young people, has disseminated recommendations on the individual approach, in order to make the commission of sexual risk behavior less attractive. Likewise, it raises others, aimed at social and community approaches aimed at collective health care as an organized group in which individuals cohabit. For its part, the international federation of pediatrics and gynecology of adolescence promotes the teaching of educational-preventive programs on pediatric and gynecological and obstetric issues, under the premise of inducing health professionals throughout the world to participate more intensively in the activities of education for sexual health and other matters related to this topic. (8) The social group that experiences the highest risk of suffering from sexually transmitted diseases are adolescents, who tend to base their level of maturity on sexual participation, reaffirming their virility or femininity in sexual practice with different partners, becoming promiscuous and make easy prey of this type of disease ${ }^{.8-10}$ 


\section{Material And Methods:-}

The present study is descriptive, cross-sectional, and retrospective observational carried out in the General Hospital of Escárcega, Campeche "Dr. Eduardo Boldo. " The universe of work consisted of all patients diagnosed with cervicovaginitis who attended the Pap smear during the period from January 2017 to December 2018.

The variables to be investigated were the following: age of the patient, age at the beginning of sexual life, number of sexual partners, economic level, sexual behavior, planning method used, school level, marital status.

\section{Results:-}

During the period from January 2017 to December 2008, the results obtained from a total of 460 patients who attended the Pap smear, 60 of these were poorly taken and the repetition of the shot was needed, 281 were negative with inflammatory process and without infection, 39 presented data of CIN II -NIC III, 80 gave results of cervicovaginitis of these 33 reported candida (41.25\%), 20 Trichomonas (25\%), 26 bacterial vaginosis (32.5\%), 1 clamydia, $(1.25 \%)$, the rest reported negative with inflammatory process.

In the patients that resulted with candida of the 33 people 7 were found in the range of 15 to 19 years, 4 in the range of 20 to 24,4 in the range of 25 to 29 years, 7 in the 30 to 34years, 5 in the 35 to 39,5 in the 40 to 44,1 of 45 to 49 .

In bacterial vaginosis of the 26 patients, 8 in the 15 to 19 years, 2 were in the range of 20 to 24 years, 2 in the 25 to 29 years, 3 in the 30 to 34,5 in the 35 a 39, 5 in the 40 to 44,1 of 45 to 49 years. In the trichomonas it was presented of the 20 patients, 2 in the range of 15 to 19 years, 7 was in the range of 20 to 24 years, 2 in the 25 to 29,3 in the range of 30 to 34 years, 3 in the 35 to 39 years, 2 in the 40 to 44,2 in the 45 to 49 . It was found that 36 of the patients studied were in free union, 20 were married, 24 single. In the three entities that studied the largest number of patients reached a full secondary level, of the 80 studied, 30 finished secondary, primary 26, illiterate 15 and high school 9. The beginning of sexual life of the 80 patients, 61 They are in the range between 15 to 19 years of age, 17 in the range of 20 to 24 years and 2 of 25 to 29 years.

Of the 80 with the diagnosis, 46 of the patients studied in terms of the number of sexual partners was presented in those who had two or more sexual partners, 34 only one sexual partner. The level that predominated in this study was level 1 was presented in 55 of the patients, 20 in level 2, 5 in level $3 \mathrm{e}$ in the 80 patients, 22 used as oral contraceptive method, 17 with hormonal IUD, 9 hormonal injectables, 5 condom, 20 did not use any method. 7 hysterectomy.

\section{Discussion:-}

Cervicovaginitis represents a cause of concern and demand for health services by the female population of childbearing age, with the most affected group being 18 to 35 years old; stage in which the woman has been considered of greater reproductive activity as well as of sexual activity. In this study it was found that the sexual behavior of the female population initiating active sexual life at an earlier age influences the presentation of this disease with a range between 15 to 19 years of age, this fact is consistent with the studies reviewed, in different countries where there is a dramatic increase in the percentage of adolescent women, who have sex as a starting factor for a set of gynecological complications, or sequelae.

In similar studies it was found that the high educational level that young people have reached in our country, has destroyed myths and taboos that saw sex as something sinful; For this reason, this population is at greater risk. In this study, it was found that the average school level has a higher risk of genital infection, probably due to the joint participation of both sexes in social and school activities, which has facilitated the approach of young people or adolescents in this stage of strong sexual impulses, factor that leads to an increase in sexually transmitted diseases.

According to the majority of the studies, there is a directly proportional relationship between the number of sexual partners and the risk of acquiring cervicovaginitis in any of its etiologies, in our study we were able to corroborate this information since the vast majority of the patients surveyed had two or more sexual partners throughout his life.

Among the predisposing factors for the development of vaginal candidiasis is the use of oral hormones, decreasing lactobacilli, through a mechanism known as "resistance to colonization", producing the proliferation of opportunistic fungi, same data are related in a direct to those thrown by this study since most of the patients used this method of planning. 
In previous works, the lack of resources to cover basic expenses is one of the reasons that stood out since the limitation of financial resources is often related to poor personal hygiene, as well as ensure that for this reason patients do not attend their medical check-up, in our study the majority counted with poverty grade one, which only count on enough for the basic needs, leaving aside the personal hygiene, not concordando in which related to the medical attention since the population in study counts on medical services free

\section{Graph}

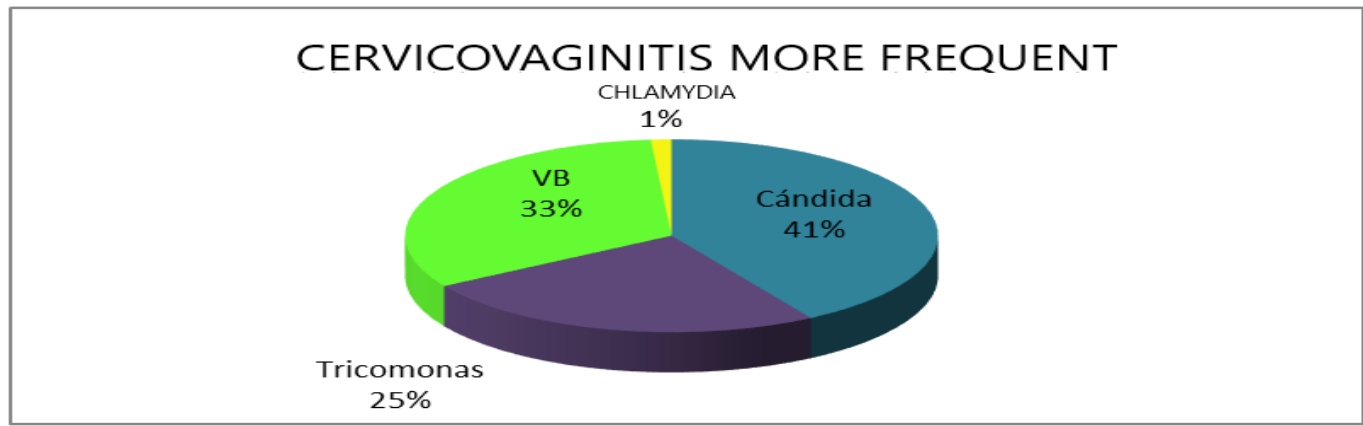

Source: H. G. E clinical record

Graph 2

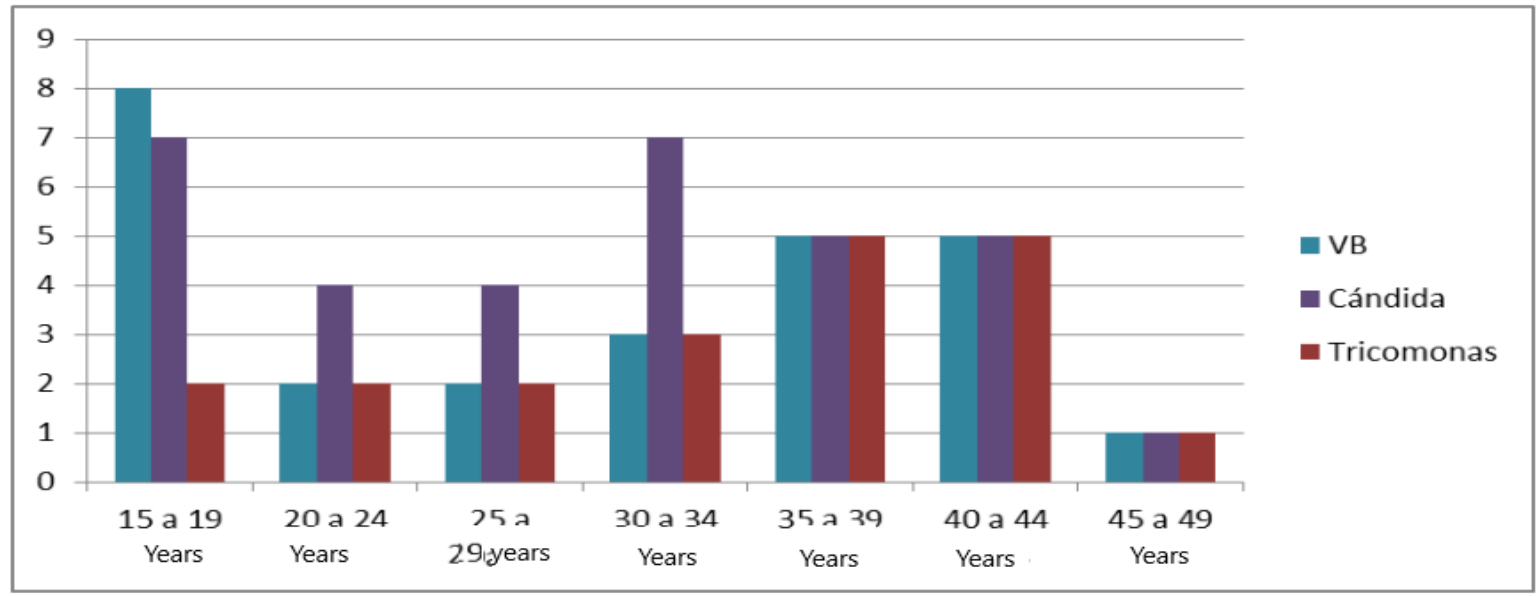

Source: H. G. E clinical record

Graph 3

\section{School Level}
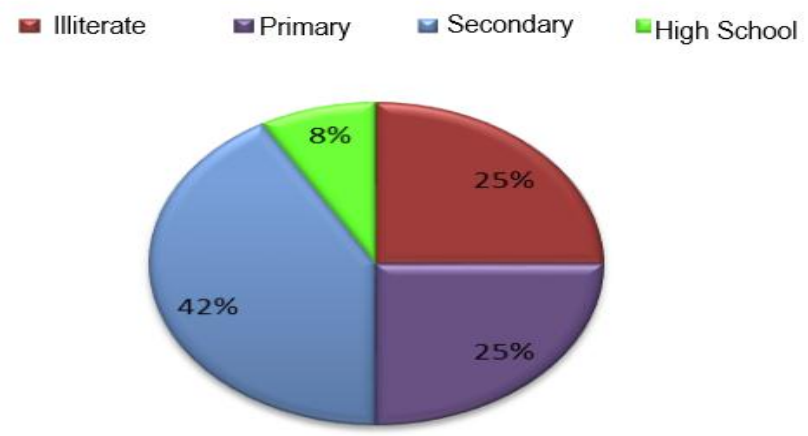

Source: H. G. E clinical record 
Graph 4:-Start of sexual life

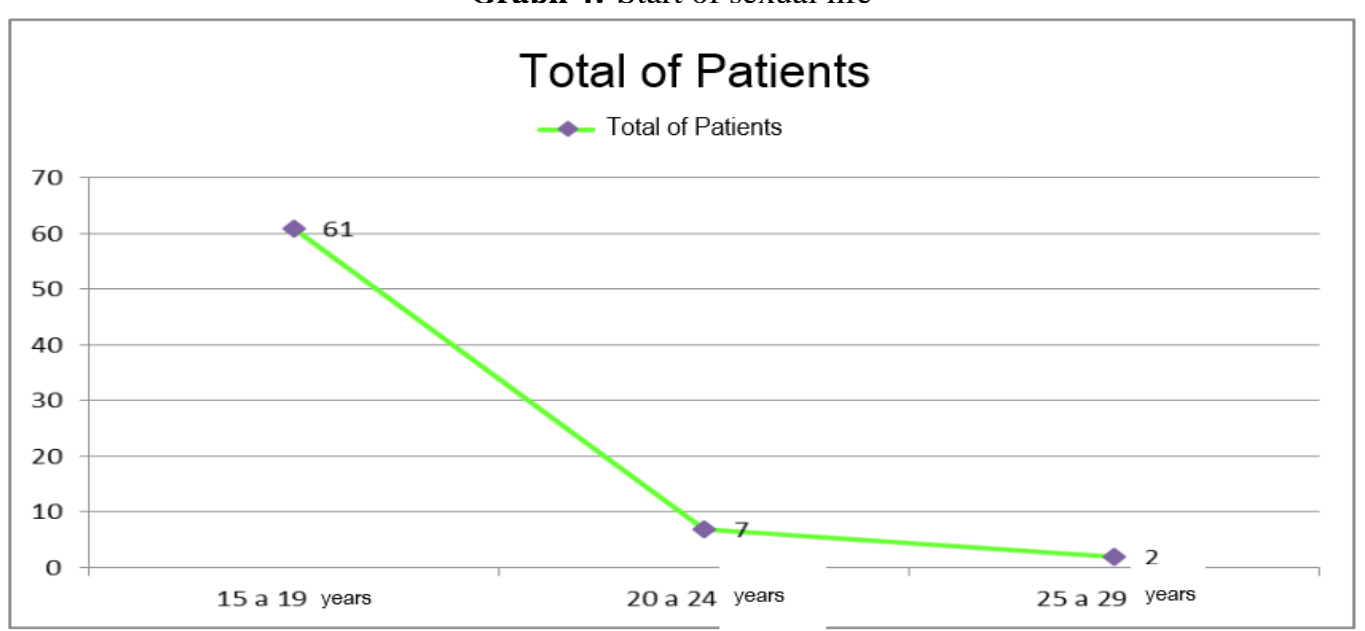

Source: H. G. E clinical record

Graph 5:-Number of sexual partners.

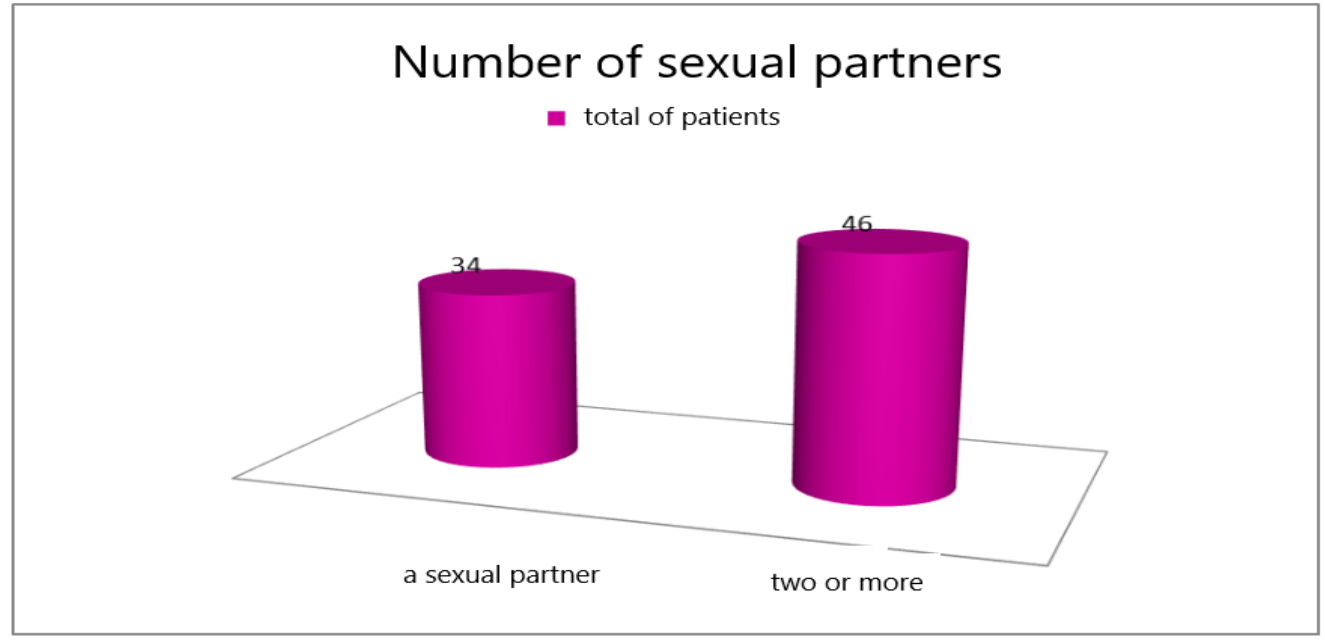

Source: H. G. E clinical record

Graph 6:-Marital Status

\section{Total of patients}

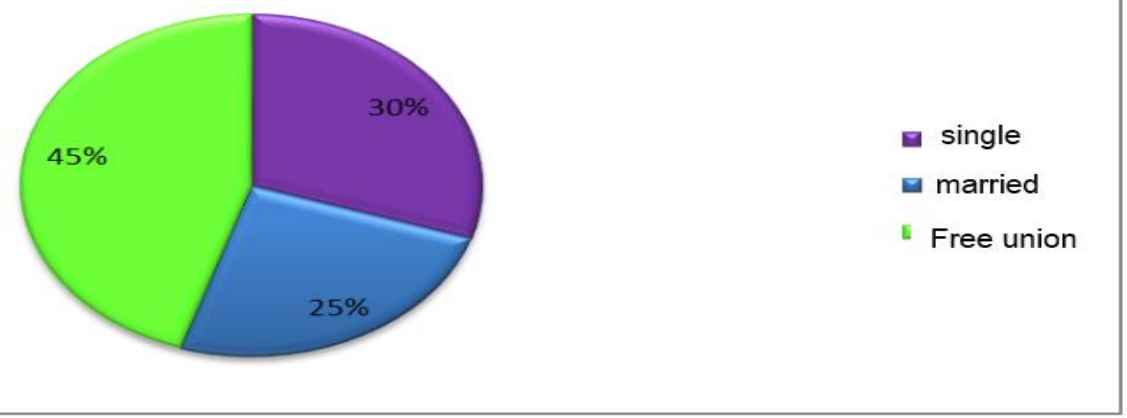

Source: H. G. E clinical record 
Graph 7:-Contraceptive Methods:

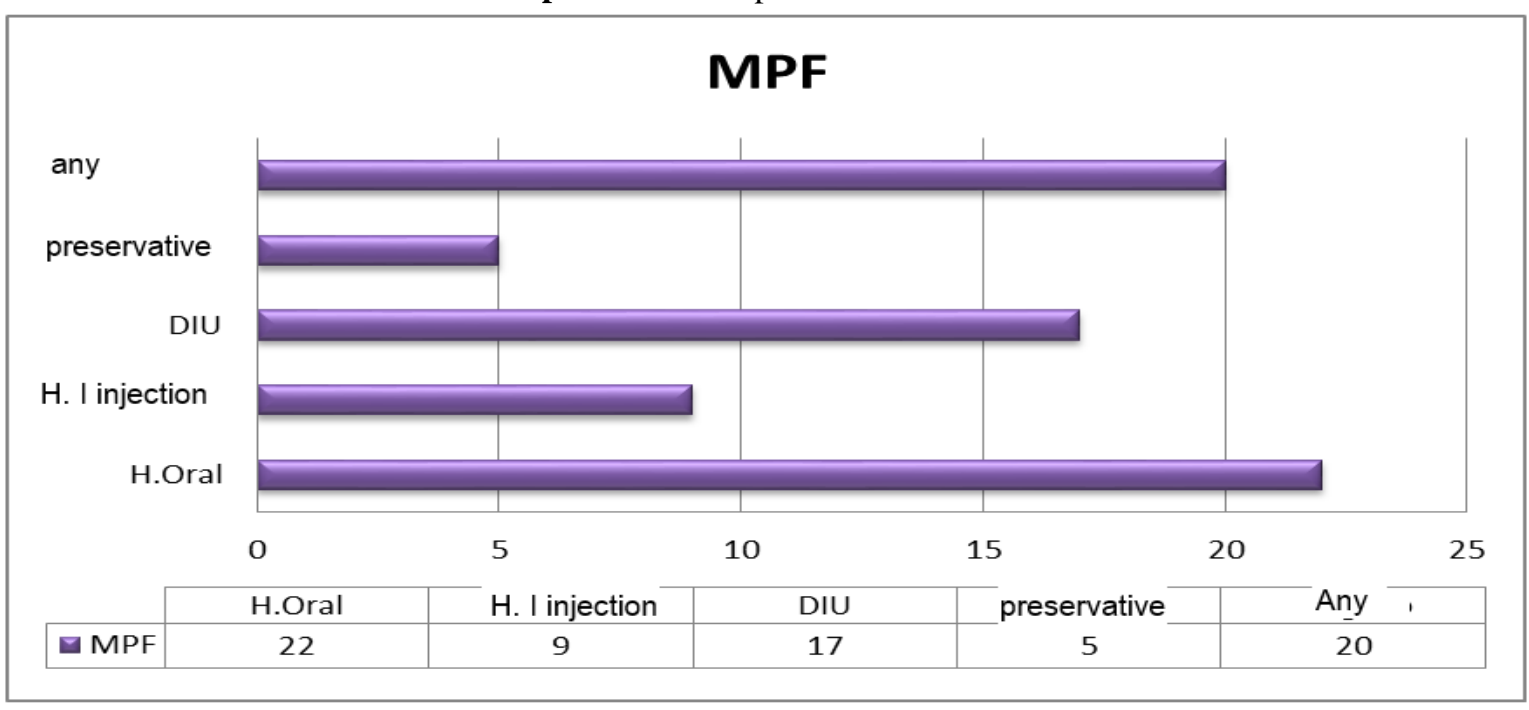

Source: H. G. E clinical record

Graph 8:-Level Of Poverty

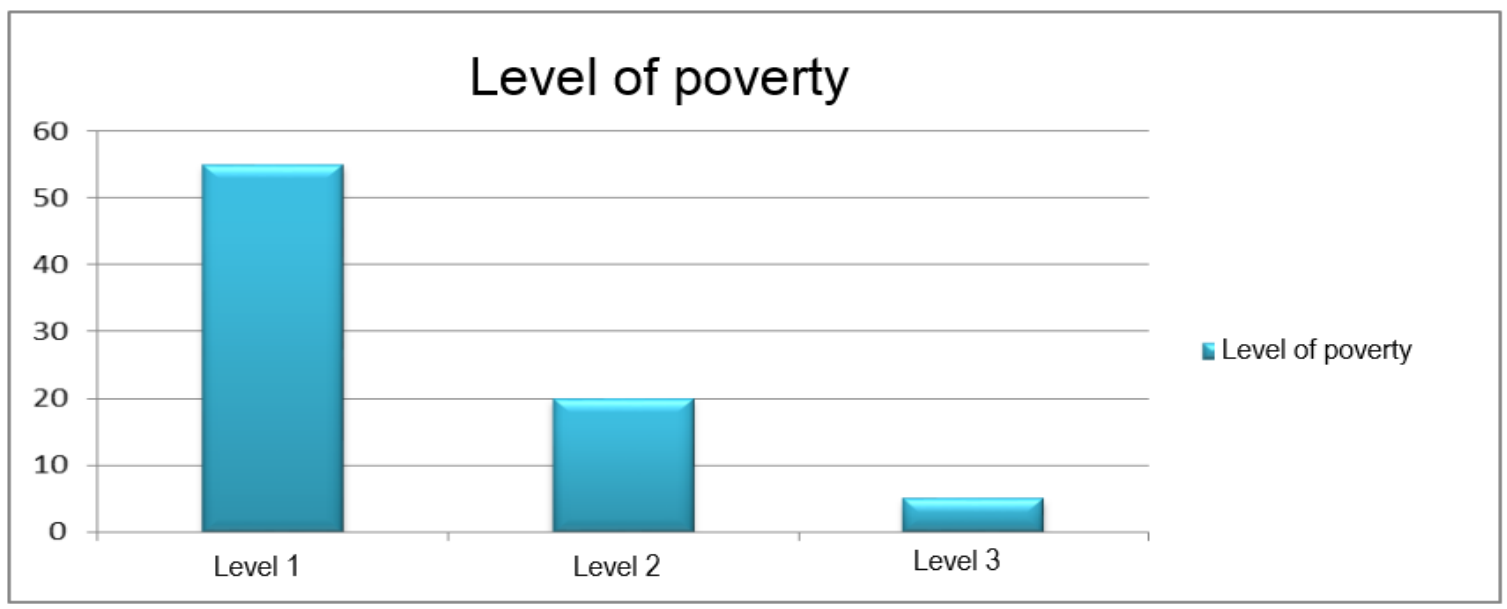

Source: H. G. E clinical record

\section{References:-}

1. López Álvarez et al Guías clínicas vulvovaginitis 2006 (recuperado) 10/02/2007

http://www.fisterra.com/guias2/vaginitis.asp.

2. Manual de salud reproductiva en la adolescencia, Aspectos básicos y clínicos, vol.30,2005

3. http://www.youngwomenshealth.org/spvag.html

4. Trejo y Pérez et al Revista medica del IMSS 200641 (suple) S71-S76 Guía clínica para el diagnostico, tratamiento y prevención de cervicovaginitis por bacterias, tricomonas y candida vol. 41 Pág.71-76.

5. http://med.unne.edu.ar/revista/revista102/infec_trac_genit.html

6. http://www.slideshare.net/UABCMEDICINA/cervicovaginitis-y-enfs-benignas-de-la-vulva/

7. Biblioteca medica, Vaginitis y vaginosis aspectos generales, 2006 (Recuperado) 14 Marzo-2006. http://www.elamal.com/content/library/home.vm?linkto=28

8. Taylor Robert 2001 Medicina de familia principios y practica editorial Springer Verlag Ibérica.

9. Beltrán Montoya et al 2002 Infección cervicovaginal como factor de riesgo para parto pretermino Ginecología y obstetricia de México vol. 70 Pág. 203-209

10. Revista de enfermedades infecciosas y microbiología, volumen 23, numero 3 julio del 2003. 